\title{
CONTRATO DE SERVIÇOS ESSENCIAIS: FORNECIMENTO DE ENERGIA ELÉTRICA
}

ESSENTIAL SERVICES CONTRACT: SUPPLY OF ELECTRICAL ENERGY

Cauê Varjão de LIMA ${ }^{1}$

ISSUE DOI: $10.21207 / 1983.4225 .437$

\section{RESUMO}

Trata-se de um artigo acadêmico desenvolvido com o intuito de estudar os contratos de serviços essenciais, em especial os de fornecimento de energia elétrica. A justificativa se dá pelo fato de os contratos estarem presentes no nosso cotidiano e pela importância que possuem na vida civil, principalmente os de serviços essenciais. Tem por objetivo poder analisar com mais liberdade os aspectos de formação do contrato, suas cláusulas, suas particularidades e também, não podendo ficar de fora, os aspectos gerais de qualquer serviço essencial.

Palavras-chave: Serviços Essenciais. Fornecimento. Contrato. Energia Elétrica. Adesão.

\section{ABSTRACT}

It is an academic paper developed with the purpose of studying the essential service contracts, especially those of electricity supply. The justification is given by the fact that the contracts are present in our daily life and by the importance they have in civil life, especially those of essential services. Its purpose is to be able to analyze more freely the aspects of contract formation, its clauses, its particularities and also, and can not be left out, the general aspects of any essential service.

Keywords: Essential Services. Supply. Contract. Electricity. Accession

\footnotetext{
${ }^{1}$ Graduando em Direito na Universidade Estadual Paulista campus de Franca (4 ${ }^{\circ}$ semestre). E-mail: cauevarjao@gmail.com
} 


\section{INTRODUÇÃO}

O presente artigo irá tratar sobre os contratos de serviços essenciais, em especial sobre os de fornecimento de energia elétrica. Essa abordagem mais incisiva em uma espécie de prestação de serviço se dá em razão das diversas particularidades que cada serviço essencial possui, com órgãos reguladores independentes, resoluções específicas e problemas formais e materiais específicos de cada tipo de serviço essencial. Será uma abordagem feita dando foco ao contrato, sobre como e por quem é estabelecido e regularizado, sua estrutura, os direitos do usuário e como seus aspectos contratuais se encaixam nas características do contrato de adesão.

Como já dito, será feito um estudo com base no fornecimento de energia elétrica e suas condições e para isso é necessário o entendimento da resolução normativa 414 de 2010, estabelecida pela Agência Nacional de Energia Elétrica (ANEEL), e como disposição geral, o estudo será feito sobre as unidades consumidoras do grupo $\mathrm{B}$, que segundo a resolução 414/10, art. $2^{\circ}$, XXXVIII, é o "grupamento composto de unidades consumidoras com fornecimento em tensão inferior a $2,3 \mathrm{KV}$, caracterizado pela tarifa monômia". Esse grupo é subdividido em residencial, rural, demais classes e iluminação pública, ou seja, não são os grandes clientes, as indústrias, com altos gastos de energia, são os meros mortais, consumidores comuns. A escolha por maior atenção aos consumidores do grupo B se dá, pois são os do nosso cotidiano, tendo assim maior utilidade prática para o presente artigo.

\section{1 ÓRGÃO REGULADOR - ANEEL}

A Constituição Federal de 1988, em seu art. 175, já previa que os serviços públicos poderiam ser oferecidos pelo regime de concessão ou permissão, tendo a lei como a maior reguladora do regime das empresas concessionárias, da fiscalização e rescisão da concessão, dos direitos dos usuários, da política tarifária e da obrigação de manter serviço adequado. A década de 1990 foi o período do Estado brasileiro em que se houve uma enorme reformulação no modo como se daria a sua presença, deixando de ser um intervencionista ou investidor do sistema econômico, para assumir uma posição mais de gestor da economia. Desse modo, iniciou-se o processo de desestatização através de concessões, permissões e privatizações com previsão legal na Lei 8.987/95, em especial para o setor elétrico na Lei 
9.074/95. No ano seguinte, a Lei 9.427/96 instituiu a Agência Nacional de Energia Elétrica (ANEEL), uma autarquia em regime especial, vinculada ao ministério de Minas e Energia, que, segundo art. $2^{\circ}$ da mesma lei, estabelece que ela "tem por finalidade regular e fiscalizar a produção, transmissão, distribuição e comercialização de energia elétrica, em conformidade com as políticas e diretrizes do governo federal".

A direção desse órgão se dá por um Diretor-Geral e quatro Diretores, em regime de colegiado, nomeados pelo Presidente da República e tendo entre suas diversas atribuições estabelecer o valor da tarifa de energia elétrica no país, ou seja, ainda cabe ao governo brasileiro estabelecer o valor da tarifa pago pelos usuários. O valor da tarifa não pode ser atribuído de forma arbitrária ou aleatória, visto que o Código do Consumidor no art. 39, inciso 10 classifica como prática abusiva a elevação sem justa causa do preço de produtos ou serviços.

Definição de tarifa segundo a própria ANEEL:

A tarifa visa assegurar aos prestadores dos serviços receita suficiente para cobrir custos operacionais eficientes e remunerar investimentos necessários para expandir a capacidade e garantir o atendimento com qualidade. Os custos e investimentos repassados às tarifas são calculados pelo órgão regulador, e podem ser maiores ou menores do que os custos praticados pelas empresas. $^{2}$

Valendo-se que a ANEEL foi estabelecida e permanece em um Estado Democrático de Direito, no qual se valorizam e exercitam os valores democráticos, não poderia esse órgão regulador tomar atos unilaterais, sem levar em consideração os pleitos, opiniões e sugestões dos consumidores. Por isso, segundo a Lei 9.247/96 que em seu art. $4^{\circ}, \S 3^{\circ}$ estabelece que processo decisório que implique na afetação de direitos dos agentes econômicos do setor elétrico ou consumidores, mediante iniciativa de projeto de lei ou, quando possível já que algumas situações no setor elétrico dependem do dinamismo e de uma resposta rápida e efetiva, por via

\footnotetext{
${ }^{2}$ Disponível em <http://www.aneel.gov.br/entendendo-a-tarifa/-/asset_publisher/uQ5pCGhnyj0y/content/parcela-b/654800?inheritRedirect=false \&redirect=http $\% 3 \mathrm{~A} \% 2 \mathrm{~F} \% 2 \mathrm{Fhwe} 100 \% 3 \mathrm{~A} 8080 \% 2 \mathrm{Fweb} \% 2 \mathrm{Fguest} \% 2 \mathrm{Fentendendo-a-ta-}$ rifa\%3Fp_p_id\%3D101_INSTANCE_uQ5pCGhnyj0y\%26p_p_lifecycle\%3D0\%26p_p_state\%3Dnormal\%26p_p_mode\%3Dview\%26p_p_col_id\%3Dcolumn2\%26p_p_col_pos\%3D1\%26p_p_col_count\%3D2.> Acesso em 26 nov. 2016
} 
administrativa, será precedido de audiência pública convocada pela própria ANEEL, ou seja, quando for se tomar alguma decisão que implique em alguma consequência de direito para os consumidores será necessária uma audiência pública. $\mathrm{O}$ intuito dessas audiências públicas, conforme o Decreto $n^{\circ} 2.335$ de 1997 em seu art.21, é a de:

I - recolher subsídios e informações para o processo decisório da ANEEL;

II - propiciar aos agentes e consumidores a possibilidade de encaminhamento de seus pleitos, opiniões e sugestões;

III - identificar, da forma mais ampla possível, todos os aspectos relevantes à matéria objeto da audiência pública;

IV - dar publicidade à ação regulatória da ANEEL.

Dessa forma, fica evidente que a ANEEL é um órgão regulador que tem por excelência a valorização e o exercício de práticas que gozam de legitimidade, transparência e que contêm espaço democrático para a deliberação dos atos que regulam o setor elétrico nacional.

Em um campo mais geral do Direito Administrativo, em especial o regime de concessão, é interessante deixar ressaltado que o poder concedente, o Estado, ao oferecer a prestação de serviço público para algum ente privado, não se exime da responsabilidade de ofertar o melhor serviço possível para o interesse público; também se trataria de uma imensa irresponsabilidade, deixar na mão do poder privado todo o modo de como se deve atuar durante a prestação do serviço público, por isso, de acordo com Bandeira de Mello, o poder concedente possui:

O poder de alteração unilateral das cláusulas regulamentares confere-lhe a possibilidade de alterar as condições do funcionamento do serviço. Por isso, pode impor modificações relativas à organização dele, a seu funcionamento e desfrute pelos usuários, o que inclui, evidentemente, as tarifas a serem cobradas. $\mathrm{O}$ concessionário não se pode opor às alterações exigidas, nem esquivar-se de cumpri-las ou reclamar a rescisão da concessão, desde que o objeto dela não haja 
sido desnaturado ou desvirtuado pelas modificações impostas. 3

\subsection{RESOLUÇÃO 414/2010}

Conforme dito no tópico anterior, a ANEEL, ao tomar alguma decisão por via administrativa, pode ser precedida de audiência pública, sendo isso que ocorreu entre $1^{\circ}$ de fevereiro a 23 de maio de 2008. E entre 09 de janeiro a 27 de março de 2009 ocorreu a Consulta Pública n $^{\mathbf{o}}$ 002/2009, em que se receberam sugestões de concessionárias e de agentes do setor e da sociedade em geral, que foram importantes para o aperfeiçoamento e atualização das condições gerais de fornecimento de energia elétrica, resultando na resolução normativa $n^{\circ}$ 414/2010.

Nessa resolução, estabeleceram-se os seguintes assuntos: as definições gerais, o atendimento inicial, as modalidades tarifárias, as cláusulas dos contratos (aspecto fundamental para estudo do presente artigo), a medição para faturamento, a leitura, a cobrança e o pagamento, a fatura, o inadimplemento, os procedimentos irregulares, as responsabilidades da distribuidora, as responsabilidades do consumidor, a suspensão do fornecimento, o atendimento ao público, o ressarcimento de danos elétricos e ainda disponibilizou o modelo de como deve ser o contrato que estabelece relação entre o consumidor/usuário e a concessionária, tal documento que irá ser analisado no tópico seguinte. Concluindo essa parte, temos que ANEEL aprova as normas e os regulamentos, os quais serão vinculados às cláusulas do contrato de serviço essencial.

\section{CONTRATO DE SERVIÇO ESSENCIAL}

O modelo de contrato que a ANEEL estipula se encontra na resolução 414/2010; nele constam as definições e sete cláusulas já predispostas (objeto, principais direitos do consumidor, principais deveres do consumidor, suspensão do fornecimento, execução de serviços e contribuições de caráter social, encerramento da relação contratual). Essa predisposição abre margem para a discussão sobre o contrato de prestação de serviço

\footnotetext{
${ }^{3}$ MELLO, Celso Antônio Bandeira de. Curso de Direito Administrativo. 32º ed. rev. e atual. até a Emenda Constitucional 84, de 2.12.2013 São Paulo: Malheiros Editores, 2015, p.754.
} 
público de energia elétrica ser um contrato de adesão. O próprio modelo de contrato se refere "na forma deste Contrato de Adesão"; Carlos Roberto Gonçalves dá, em sua doutrina, como exemplo de contrato de adesão "os celebrados com as concessionárias de serviços públicos (fornecedoras de água, energia elétrica etc.)."4

No entanto, uma visão minoritária da doutrina entende de forma divergente, entre eles, Sílvio de Salvo Venosa que vê no contrato de serviço essencial de fornecimento de energia elétrica uma forma peculiar de contrato, denominado coativo, pois:

Se, por um lado, a concessionária não pode negar o serviço público, na prática, o usuário não pode também dele prescindir. Ambas, as partes são forçadas a contratar. A interpretação das cláusulas e o inadimplemento, nesse caso, não podem ser vistos de forma igual aos demais contratos, nem mesmo aos contratos de adesão. ${ }^{5}$

A doutrina majoritária, assim como a própria ANEEL, definem como contrato de adesão, então será essa a visão adotada, sendo feita uma maior análise em tópico subsequente. Tanto que a inalterabilidade do documento é para ambos os lados, já que o contrato de adesão "é o instrumento com cláusulas vinculadas às normas e regulamentos aprovados pela ANEEL, não podendo o conteúdo das mesmas ser modificado pela concessionária ou consumidor, a ser aceito ou rejeitado de forma integral". 6

Para se iniciar um contrato, é necessário que o consumidor realize um pedido formal junto à distribuidora. Segundo a ANEEL, na resolução 414/2010 no art. $2^{\circ}$, inciso LXXIII, solicitação de fornecimento é:

Ato voluntário do interessado na prestação do serviço público de fornecimento de energia ou conexão e uso do sistema elétrico da distribuidora, segundo disposto nas normas e nos respectivos contratos, efetivado pela alteração de titularidade de unidade consumidora que

\footnotetext{
${ }^{4}$ GONÇALVES, Carlos Roberto. Direito civil brasileiro, volume III: contrato e atos unilaterais. 5.ed. rev. e atual. São Paulo: Saraiva, 2008, p.75.

${ }^{5}$ VENOSA, Sílvio de Salvo. Direito civil: teoria geral das obrigações e teoria geral dos contratos. 6 . ed. São Paulo: Atlas, 2006, p.384.

${ }^{6}$ ALVARENGA, Maria Amália Figueiredo Pereira; Volpe Filho, Clovis Alberto. Setor Elétrico: Aspectos Jurídicos Relevantes. 1. ed. Curitiba: Juruá, 2008, p.125.
} 
permanecer ligada ou ainda por sua ligação, quer seja nova ou existente.

Essa solicitação deve ser feita pelo consumidor, podendo ser uma pessoa física ou jurídica, de Direito público ou privado, ou seja, será a pessoa que irá contratar o serviço de fornecimento de energia elétrica ficando sujeita aos deveres impostos a ela e aos seus direitos, sendo que esse rol de direitos e deveres está contido no contrato de forma mais específica, principalmente a de caráter técnico, na resolução 414/2010 da ANEEL e outros atos normativos esparsos.

Ao se iniciar um contrato com a concessionária de energia elétrica, é fundamental ter em mente que o contrato de fornecimento é personalíssimo, ou seja, como são precisas as palavras de Volpe Filho e Maria Amália Alvarenga: "o consumidor não pode ser responsabilizado por inadimplência anterior à sua efetiva entrada na unidade de consumo" ". Eis uma jurisprudência que confirma o entendimento:

PRESTAÇÃO DE SERVIÇOS. FORNECIMENTO DE ENERGIA ELÉTRICA. DECLARATÓRIA DE INEXISTÊNCIA DE DÉBITO C.C. INDENIZAÇÃO POR DANO MORAL. 1. O locatário só pode ser responsabilizado pelo pagamento dos débitos referentes à prestação dos serviços de energia a partir de sua posse. 2. A indevida inscrição do nome do consumidor nos cadastros de proteção ao crédito ultrapassa o mero dissabor, gerando inconteste abalo moral e justificando a reparação do dano daí decorrente e oriundo do agir indiligente da ré. 3 . O valor do dano moral deve ser aferido com razoabilidade, sem excesso, para que não gere enriquecimento, nem com insignificância, que o torne inexpressivo. Sentença mantida. Recurso desprovido. ${ }^{8}$

A vigência do contrato de fornecimento de energia elétrica terá um prazo de doze meses, conforme o art. $63, \S 3^{\circ}$ da resolução normativa da ANEEL 414/2010 e a prorrogação será automática por mais doze meses

\footnotetext{
${ }^{7}$ ALVARENGA, Maria Amália Figueiredo Pereira; Volpe Filho, Clovis Alberto. Setor Elétrico: Aspectos Jurídicos Relevantes. 1. ed. Curitiba: Juruá, 2008, p.124.

${ }^{8}$ TJSP. Tribunal de Justiça de São Paulo. Relator(a): Felipe Ferreira; Comarca: São Paulo; Órgão julgador: $25^{\mathrm{a}}$ Câmara Extraordinária de Direito Privado; Data do julgamento: 17/11/2016; Data de registro: $17 / 11 / 2016$.
} 
caso o consumidor não venha se manifestar expressamente de forma contrária à prorrogação.

Dentro do rol de deveres do consumidor, os mais importantes são: manter adequadas e seguras as instalações elétricas, conservar qualquer equipamento da concessionária em sua posse, pagar a fatura da energia dentro do prazo devido, manter os dados técnicos e pessoais atualizados.

No que se refere à suspensão do fornecimento, a cláusula quarta do modelo de contrato dispõe:

Não se caracteriza como descontinuidade do serviço a sua interrupção imediata, pelas razões descritas nos itens 1 e 2 seguintes, ou após prévio aviso, pelas razões descritas nos itens 3 a 5 :

1. deficiência técnica ou de segurança em instalações da unidade consumidora que ofereçam risco iminente de danos a pessoas, bens ou ao sistema elétrico;

2. fornecimento de energia elétrica a terceiros;

3. impedimento do acesso de empregados e representantes da distribuidora para leitura, substituição de medidor e inspeções necessárias;

4. razões de ordem técnica; e

5. falta de pagamento da fatura de energia elétrica.

A suspensão do fornecimento de energia elétrica é extremamente controversa tanto na doutrina quanto na jurisprudência, pois de um lado, temos a compreensão de que é inconstitucional o corte de energia em razão da inadimplência, podendo se entender que:

A suspensão viola o inciso XXXV e o LV, do art. $5^{\circ}$ da Constituição. Viola o primeiro, pois, a partir do momento em que a concessionária de energia elétrica se arroga no direito de suspender o fornecimento, está a subtrair do crivo do poder judiciário monopólio da Jurisdição, e fere o segundo em virtude de estar a 
concessionária cerceando ao usuário o contraditório, ou melhor, do devido processo legal ${ }^{9}$

Além de que, o corte no fornecimento de energia de forma abrupta e traumática, deixando a pessoa sem o mínimo para manutenção de requisitos básicos, como, por exemplo, a refrigeração de alimentos, seria uma afronta à dignidade humana; por outro lado, o parágrafo $3^{\circ}$ da Lei $n^{\circ}$ $8.987 / 95$, art. $6^{\circ}$ diz que não caracteriza como descontinuidade do serviço a interrupção ocasionada por inadimplemento do usuário levando em consideração o interesse público e também seja o cliente previamente avisado. Incluindo também o art. 22 do Código de Defesa do Consumidor que prevê que as concessionárias de serviço público têm a obrigação de realizar seus serviços de forma continuada quando essenciais, mas esse artigo não é visto de maneira absoluta, podendo suspender o fornecimento de energia no caso de inadimplência. Portanto, se não for de interesse público ou essencial a continuidade do fornecimento de energia, a concessionária terá que avisar o cliente previamente que a energia será suspensa por razões de inadimplência, se assegurando ao usuário o contraditório e ampla defesa nos procedimentos administrativos e judiciais.

Sobre o encerramento da relação contratual, tanto o contrato, quanto a resolução 414/2010 em seu art. 70, estabelecem que se dará por encerrado a relação com o pedido voluntário do titular da unidade consumidora ou pela própria concessionária, caso se passem dois ciclos completos de faturamento após a suspensão regular e ininterrupta do fornecimento à unidade consumidora; também se prevê o fim da relação contratual caso um terceiro venha realizar um pedido de fornecimento formulado por novo interessado referente à mesma unidade consumidora.

\section{DIREITOS DO USUÁRIO}

A Constituição Federal tem como princípio basilar o da dignidade da pessoa humana, e o fato de não possuir energia elétrica em um mundo que caminha em direção, de modo irreversível, à globalização, pode ferir esse princípio de variadas maneiras, por exemplo, não poder refrigerar alimentos para a sua conservação, em casos mais urgentes não conseguir

\footnotetext{
${ }^{9}$ ALVARENGA, Maria Amália Figueiredo Pereira; Volpe Filho, Clovis Alberto. Setor Elétrico: Aspectos Jurídicos Relevantes. 1. ed. Curitiba: Juruá, 2008, p.155.
} 
manter equipamento de saúde em funcionamento e também não estar "inserido" no mundo, pois se levarmos em consideração o que Zygmunt Bauman e sua obra "Globalização e as Consequências Humanas" nos diz, podemos interpretar que quem não tem energia elétrica, consequentemente não poderá usufruir da internet, televisão, computador, portanto estará preso em seu mundo particular, e ficar preso a esse espaço em um mundo globalizado é um sinal de privação e degradação social ${ }^{10}$.

Dentro do rol de direitos do usuário, sem sombra de dúvidas, estão todos aqueles assegurados, caso não haja disposição em contrário, os do Código de Defesa do Consumidor que prevê no:

Art. 22. Os órgãos públicos, por si ou suas empresas, concessionárias, permissionárias ou sob qualquer outra forma de empreendimento, são obrigados a fornecer serviços adequados, eficientes, seguros e, quanto aos essenciais, contínuos.

Parágrafo único. Nos casos de descumprimento, total ou parcial, das obrigações referidas neste artigo, serão as pessoas jurídicas compelidas a cumpri-las e a reparar os danos causados, na forma prevista neste código.

Além do entendimento doutrinário:

Adotando o pensamento em foco e acatando a incidência da Lei 8.078/90 a todos os serviços públicos, Luiz Antônio Rizzatto Nunes acredita que ficam compreendidos na regulamentação consumerista todos os serviços públicos, sem ressalvas. Isso porque as únicas exceções previstas na lei para excluir a abrangência de serviço pelo CDC foram os serviços prestados na ausência de qualquer remuneração ou custo, e os serviços de caráter trabalhista ${ }^{11}$.

Resumindo, o Código de Defesa do Consumidor abrange, como relações de consumo, serviços pagos, como consta no art. $3^{\circ}, \S 2^{\circ}$, dessa forma sendo possível a sua aplicação.

\footnotetext{
${ }^{10}$ BAUMAN, Zygmunt. Globalização - As consequências humanas. São Paulo: Zahar, 1999, passim.

${ }^{11}$ NOVAIS, Elaine Cardoso de Matos. Serviços públicos \& relação de consumo: aplicabilidade do Código de Defesa do Consumidor. Curitiba: Juruá, 2008, p.144.
} 
A ANEEL elenca os principais direitos do consumidor, sendo os mais importantes: o de fornecimento de energia elétrica com qualidade e continuidade; vistoria dos medidores de consumo de energia; no caso de inexistência de medidores, o faturamento deverá ser feito com base nos valores mínimos faturáveis; ter a entrega da fatura em outro local que não a unidade consumidora, devendo arcar com eventuais custos adicionais; disponibilização de seis datas de vencimento da fatura, para a escolha do consumidor; se houver pagamento em duplicidade da fatura, a concessionária deverá fazer a devolução até o próximo vencimento; no caso de suspensão indevida, a concessionária deverá providenciar a religação, sem qualquer ônus, no prazo máximo de 4 horas após o pedido; está o consumidor assegurado do ressarcimento por danos ocasionados em virtude do fornecimento de energia elétrica; ser avisado com 15 dias de antecedência, no caso de suspensão do fornecimento por falta de pagamento e os consumidores que possuírem equipamento vital na unidade consumidora e dependem da eletricidade, deverão ser avisados sobre interrupções programadas, com antecedência mínima de 5 dias úteis. ${ }^{12}$

É importante o entendimento de que, ao tratarmos de concessão de serviços essenciais, alguns direitos necessitam ser respeitados pela concessionária, incluindo os de fornecimento de energia elétrica, lembrando de que se trata de um serviço, cujo intuito é satisfazer o bem comum, a ordem e a paz social. Por isso, como já foi mencionado acima, o Poder Público teve a necessidade de estabelecer o regime de concessão e, incluiu aqui, os direitos dos usuários. Sendo precisas as palavras do administrativista Bandeira de Mello:

A Lei 8.987, de 13.2.1995, que, em cumprimento ao citado art. 175 dispõe sobre o regime de concessão e permissão de serviços públicos, em seu art. $7^{\circ}$ arrola inúmeros direitos dos usuários, a saber: I- receber serviço adequado, o qual a teor do art. $6^{\circ}, \S 1^{\circ}$, é o que satisfaz as condições de regularidade, continuidade, eficiência, segurança, atualidade, generalidade, cortesia na sua prestação e modicidade das tarifas. Tal modicidade, registre-se, é um dos mais relevantes direitos do usuário, pois, se for desrespeitada, o próprio

\footnotetext{
${ }^{12}$ Disponível em <http://www2.aneel.gov.br/aplicacoes/direitos_e_deveres/> Acesso em 28 de nov. 2016.
} 
serviço terminará por ser inconstitucionalmente sonegado. $^{13}$

Portanto, reforçando a ideia de que o usuário possui do seu lado as normas que estabelecem como deverá ser prestado o serviço em regime de concessionária, sendo que o preço da tarifa cobrada deverá respeitar o princípio da modicidade, pois a energia elétrica é um bem necessário a todos, e este não poderia vir a ser cobrado como um bem de luxo ou prestado de forma precária.

\section{CONTRATO DE ADESÃO}

Neste tópico, será tratado sobre o contrato de adesão e suas características, e como algumas delas se encaixam no contrato de serviços essenciais. Como dito em tópico acima, classificar o contrato de prestação de serviço essencial como de adesão é o entendimento da ANEEL e de diversos doutrinadores, entre eles Gonçalves, porém outros divergem, a título de exemplo, Sílvio Venosa.

Na realidade, os contratos de adesão são uma espécie de contrato extremamente polêmica; alguns até cogitam considerá-lo inconstitucional, outros, tentando pacificar entendimento, tentam classificá-lo como uma espécie sui generis de contrato. A discussão se dá, pois, no modelo clássico de contrato: pressupunha-se para sua existência a autonomia das vontades, a negociação, o diálogo, a barganha, porém o modelo de adesão sufoca essa concepção, pois, simplificando, ou você adere às cláusulas em bloco, ou você as recusa por inteiro; não existe discussão e nem meio-termo.

É necessário, inicialmente, tentar enxergar os dois lados. Porém, antes é preciso se explicitar alguns pontos do contrato de adesão: ele possui esse nome em razão da sua forma, porque ele estabelece a relação contratual, já que para sua realização se exige somente o consentimento, ou seja, a simples adesão ao conteúdo que foi preestabelecido por uma das partes, o lado mais forte da relação, pois ele consegue impor o conteúdo do contrato. Portanto, foi essa falta de uma negociação prévia do contrato, que factualmente se resumiu na mera aceitação de uma parte, com as cláusulas já estabelecidas pela outra, que confrontou o modelo clássico no qual "se

\footnotetext{
${ }^{13}$ MELLO, Celso Antônio Bandeira de. Curso de Direito Administrativo. $32^{\circ}$. ed. rev. e atual. até a Emenda Constitucional 84, de 2.12.2013 São Paulo: Malheiros Editores, 2015, p.768.
} 
postulava o contrário, que o ajuste contratual resultaria da livre negociação entre pessoas dotadas de igual capacidade jurídica" ${ }^{\prime 14}$.

Defendendo o modelo de contrato de adesão, temos como argumento que em uma sociedade complexa e dinâmica, com a massificação da produção e aumento populacional, exige-se que determinados serviços tenham um modelo contratual já preestabelecido, para garantir, de certo modo, igualdade entre os aderentes. Uma resposta ágil para quem deseja usufruir determinados serviços, pois, materialmente, não seria viável a uma concessionária realizar um contrato de fornecimento de energia elétrica especial para cada consumidor, pois, por exemplo, a concessionária Elektro Eletricidade e Serviços S/A, por volta de 2008, atendia 224 municípios do estado de São Paulo e 5 do Mato Grosso do Sul, compreendendo 2,2 milhões de cliente e com quase 1,9 milhão de unidades consumidoras residenciais $^{15}$, ou seja, seria inviável tratar cada residência especificadamente.

Por outro lado, é preocupante a situação na qual um lado da relação contratual seja infinitamente mais forte, é preciso que sejam evitados, a qualquer custo, os abusos que podem vir a ser estabelecidos pela falta da negociação entre as partes. Outro aspecto que deve ser visto com cuidado é a falta da liberdade de contratar, como Enzo Roppo diz, que o aderente:

Não é livre, sequer, na alternativa de contratar ou não contratar, porque quando a adesão ao contrato standard constitui o único meio de adquirir bens ou serviços essenciais e indispensáveis à vida de todos os dias, trata-se, na realidade, de uma escolha obrigada. ${ }^{16}$

A escolha se torna obrigada, uma escolha imposta a que o consumidor não pode se furtar, que se encaixa com o contrato de fornecimento de energia elétrica, pois a eletricidade é uma necessidade básica da vida moderna. $O$ contrato é imposto sem nenhuma negociação direta, sem opção de escolha, visto que não se possui alternativa de contratar outra concessionária no caso de unidades consumidoras tipo $\mathrm{B}$, em especial as

\footnotetext{
${ }^{14}$ NEGREIROS, Teresa. Teoria do contrato: novos paradigmas. Rio de Janeiro: Renovar, 2002, p. 363.

${ }^{15}$ Disponível em <http://www2.aneel.gov.br/arquivos/PDF/cartilha_elektro2.pdf > Acesso em 28 nov. 2016.

${ }^{16}$ Enzo Roppo. O contrato. trad. Ana Coimbra e M. Januário Gomes. Coimbra: Livraria Almedina, 1998, p.317. apud NEGREIROS, Teresa. Teoria do contrato: novos paradigmas. Rio de Janeiro: Renovar, 2002, p. 366.
} 
residenciais. Colocando o entendimento de Orlando Gomes, que se encaixa perfeitamente com trabalho, o contrato de adesão:

Por ser oferta a uma coletividade, segundo outros, por ser obra exclusiva de uma das partes, por ter regulamentação complexa, porque preponderante a posição de uma das partes ou não admitir discussão a proposta, havendo quem o explique como o instrumento próprio da prestação dos serviços privados de utilidade pública. ${ }^{17}$

No entanto, é preciso ponderar, não se pode entender que o contrato de adesão é definido unicamente pela concessionária; como já foi visto, ele é feito com base nas normas e regulamentos aprovados pela ANEEL a partir de audiências públicas. Portanto, os abusos não hão de vir no formato contratual, pois o objetivo da ANEEL é justamente o de evitar os abusos formulando o contrato, estabelecendo a tarifa, fiscalizando e regulando o setor elétrico. Talvez o abuso que ocorra seja na execução do contrato, em que a concessionária, por ser mais forte, por possuir o poder de "cortar" a luz, diversas vezes não respeita as cláusulas e o processo administrativo com direito contraditório e ampla defesa, conforme é perceptível pela jurisprudência:

APELAÇÃO - PRESTAÇÃO DE SERVIÇO - ENERGIA ELÉTRICA - FRAUDE - AUSÊNCIA DE COM$P R O V A C ̧ A \tilde{O}$ - Ausência de prova inequívoca de fraude - Procedimento administrativo sem contraditório - Ônus probatório imposto pelo art. 333, II, do CPC - Sentença mantida - Recurso não provido.

(Relator(a): Roberto Mac Cracken; Comarca: Embu das Artes; Órgão julgador: $37^{\mathrm{a}}$ Câmara de Direito Privado; Data do julgamento: 19/05/2011; Data de registro: 06/06/2011; Outros números: 990102892921)

Sendo que, como já foi dito no tópico dos direitos do usuário, a própria Constituição Federal em seu art. 5, inciso LV diz que "aos litigantes, em processo judicial ou administrativo, e aos acusados em geral são

\footnotetext{
${ }^{17}$ Orlando Gomes. Contratos. 12.ed. Rio de Janeiro: Forense, 1991, p. 128. apud NEGREIROS, Teresa. Teoria do contrato: novos paradigmas. Rio de Janeiro: Renovar, 2002, p. 361.
} 
assegurados o contraditório e ampla defesa, com meios e recursos a ela inerentes".

\section{CONCLUSÃO}

Após passarmos pelo órgão regulador do sistema elétrico, a ANEEL, apresenta a resolução que estabelece as condições gerais de fornecimento de energia elétrica, pelo contrato de serviço essencial e suas cláusulas; depois, para os direitos do usuário, traz as características do contrato de adesão e se ele se encaixa no contrato de prestação de eletricidade. Pode-se concluir que: o modelo de contrato, de certo modo, é estabelecido por um órgão regulador vinculado ao Ministério de Minas e Energia, ou seja, os direitos do usuário e a tarifa são estabelecidos pelo próprio governo federal, através de audiências públicas, nas quais os consumidores, agentes econômicos do setor e concessionárias podem dar sugestões, opiniões e informações; portanto, além da ANEEL estabelecer os direitos, a tarifa, as normas e regulamentos, é o objetivo dela fiscalizar o setor elétrico para se evitar o abuso na realização contratual e na execução deste.

Os direitos dos usuários estão expressos no contrato, que são garantidos pela resolução normativa 414/2010 da ANEEL, porém não deixar longe de vista que, por ser um contrato no qual existe remuneração por um serviço é totalmente possível o exercício e a reivindicação dos direitos expostos no Código de Defesa do Consumidor, caso não exista nenhuma disposição contrária. Além de que, em todo processo administrativo ou judicial deve ser assegurado o contraditório e a ampla defesa.

Sobre o contrato de adesão, é interessante ressaltar, que sim, o contrato de fornecimento de energia elétrica se encaixa nessa classificação contratual, porém é necessário ter cautela, pois ele não é um contrato totalmente imposto pela concessionária e ao seu gosto, já que a própria ANEEL estabelece normas e regulamentos, e o contrato é vinculado a ela. Sendo também que esse órgão atua na regulação e fiscalização, estando sempre disponível para denúncia de abusos praticados pelas concessionárias. Reafirmando, o abuso não se dá propriamente em razão do contrato, visto que esse é regulado indiretamente pelo governo federal, mas, sim, na execução dele, pois, por diversas vezes, a concessionária não respeita as cláusulas do contrato, as normas e regulamentos da ANEEL, a legislação consumerista e nem mesmo as normas constitucionais. 


\section{REFERÊNCIAS}

ALVARENGA, Maria Amália Figueiredo Pereira; VOLPI FILHO, Clovis Alberto. Setor Elétrico: aspectos jurídicos relevantes. 1. Ed. Curitiba: Juruá, 2008.

BAUMAN, Zygmunt. Globalização - As consequências humanas. São Paulo: Zahar, 1999

BITTAR, Carlos Alberto; GARCIA JÚNIOR, Ary Barbosa; FERNANDES NETO, Guilherme. Os contratos de adesão e o controle de cláusulas abusivas. São Paulo: Saraiva, 1991.

CAMPOS, Clever M. Introdução ao direito de energia elétrica. São Paulo: Ícone, 2001.

CASTRO, Marcus Faro; LOUREIRO, Luiz Gustavo Kaercher. Direito da energia elétrica no Brasil: aspectos institucionais regulatórios e socioambientais. Brasília: ANEEL, 2010.

Gonçalves, Carlos Roberto. Direito civil brasileiro, volume III: contratos e atos unilaterais. 5. ed. rev. e atual. São Paulo: Saraiva, 2008.

MARQUES, Cláudia Lima. Contratos no Código de Defesa do Consumidor: o novo regime das relações contratuais. 3.ed. rev. e atual. e ampli., incluindo mais de 625 decisões jurisprudenciais. 3. tir. São Paulo: Editora Revista dos Tribunais, 1999.

MELLO, Celso Antônio Bandeira de. Curso de Direito Administrativo. 32. ed. rev. e atual. até a Emenda Constitucional 84, 2.12.2014. São Paulo: Malheiros Editora, 2015.

NEGREIROS, Teresa. Teoria do contrato: novos paradigmas. Rio de Janeiro: Renovar, 2002.

NOVAIS, Elaine Cardoso de Matos. Serviços \& relação de consumo: aplicabilidade do Código de Defesa do Consumidor. Curitiba: Juruá, 2008.

VENOSA, Sílvio de Salvo. Direito civil: teoria geral das obrigações e teoria geral dos contratos. 6. Ed. São Paulo: Atlas, 2006.

\section{LEIS E ATOS NORMATIVOS UTILIZADOS:}

ANEEL, Resolução Normativa n 414, de 19 de setembro de 2010. Estabelece as Condições Gerais de Fornecimento de Energia Elétrica de forma atualizada e consolidada.

BRASIL. Constituição (1988). Constituição da República Federativa do Brasil de 1988. Brasília, DF: Senado Federal.

BRASIL, Lei n 8.987, de 13 de fevereiro de 1995. Dispõe sobre o regime de concessão e permissão da prestação de serviços públicos previstos no art. 175 da 
Constituição Federal, e dá outras providências. Diário Oficial [da] República Federativa do Brasil, Brasília, DF, p. 1917, 14 fev. 1995.

BRASIL. Lei $\mathrm{n}^{\circ} 8.078$ de 11 de setembro de 1990. Dispõe sobre a proteção do consumidor e dá outras providências. Diário Oficial [da] República Federativa do Brasil, Brasília, DF, p. 1, 12 set. 1990.

BRASIL, Lei $\mathrm{n}^{\circ}$. 10.406, de 10 de janeiro de 2002. Institui o Código Civil. Diário Oficial [da] República Federativa do Brasil, Brasília, DF, p. 1, 11 jan. 2002.

BRASIL, Lei $\mathrm{n}^{\circ}$ 9.074, de 7 de julho de 1995. Estabelece normas para outorga e prorrogações das concessões e permissões de serviços públicos e dá outras providências. Diário Oficial [da] República Federativa do Brasil, Brasília, DF, p. 10125,8 jul. 1995.

BRASIL, Lei $\mathrm{n}^{\circ}$ 9.427, de 26 de dezembro de 1996. Institui a Agência Nacional de Energia Elétrica - ANEEL, disciplina o regime das concessões de serviços públicos de energia públicos de energia elétrica e dá outras providências. Diário Oficial [da] República Federativa do Brasil, Brasília, DF, p. 28653, 27 dez. 1996.

BRASIL, Decreto n ${ }^{\circ} 2.335$, de 6 de outubro de 1997. Constitui a Agência Nacional de Energia Elétrica - ANEEL, autarquia sobre regime especial, aprova sua Estrutura Regimental e o Quadro Demonstrativo dos Cargos e Comissão e Funções de Confiança e dá outras providências. Diário Oficial [da] República Federativa do Brasil, Brasília, DF, p. 22377, 7 out. 1997. 